Canadian

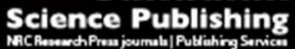

Canadian Journal of Microbiology Revue canadienne de de microbiologie

\title{
Sugar sulfates are not hydrolyzed by the acid-inducible sulfatase AsIA from Salmonella enterica Enteritidis NaIR and Kentucky 3795 at pH 5.5
}

\begin{tabular}{|r|l|}
\hline Journal: & Canadian Journal of Microbiology \\
\hline Manuscript ID & cjm-2017-0059.R1 \\
\hline Manuscript Type: & Note \\
\hline Date Submitted by the Author: & 16 -May-2017 \\
\hline Complete List of Authors: & $\begin{array}{l}\text { Ganguly, Arpeeta; University of Delaware, Animal and Food Sciencs } \\
\text { Joerger, Rolf; University of Delaware, Animal and Food Sciences }\end{array}$ \\
\hline Keyword: & $\begin{array}{l}\text { Salmonella gene, Salmonella sulfatase, acid sulfatase, sugar sulfate ester, } \\
\text { tyrosine sulfate }\end{array}$ \\
\hline \multicolumn{2}{|l}{} \\
\hline
\end{tabular}

SCHOLARONE ${ }^{m}$

Manuscripts 
Sugar sulfates are not hydrolyzed by the acid-inducible sulfatase AsIA from Salmonella enterica Enteritidis Nal ${ }^{\mathrm{R}}$ and Kentucky 3795 at pH 5.5

Arpeeta Ganguly ${ }^{\mathrm{a}}$ and Rolf D. Joerger ${ }^{\mathrm{a}^{*}}$

${ }^{a}$ Dept. of Animal and Food Sciences, University of Delaware, Newark, DE 19716 
ABSTRACT

The open reading frames (ORFs), SEN0085 and SeKA_A4361, from Salmonella enterica Enteritidis Nal $^{R}$ and Kentucky 3795, corresponding to the acid-inducible sulfatase gene, as/A from S. $e$ Typhimurium, were previously suggested by microarray analysis to be differentially expressed under acid conditions. However, growth and enzyme activity tests in the present study demonstrated that both wild type strains exhibited sulfatase activity with 4-nitrophenyl sulfate and 5-bromo-4-chloro-3 indolyl sulfate at $\mathrm{pH}$ 5.5. The acid sulfatase does not appear to be involved in sugar sulfate, tyrosine sulfate and 4hydroxy-3-methoxyphenylglycol sulfate, heparin or chondroitin sulfate hydrolysis at $\mathrm{pH}$ 5.5. Adhesion and invasion assays did not reveal differences between the serotypes and their corresponding as/A deletion mutants. Thus the role and substrate(s) of AsIA, a protein unique to Salmonella and encoded in all sequences Salmonella strains, remain elusive.

Keywords

Salmonella; acid sulfatase; sugar sulfate; 
Since 1998, Salomonella enterica serovar Kentucky has been isolated from meat and poultry products in the United States far more frequently than other serovars. For example, in $2013,28 \%$ of all Salmonella isolates from these sources were of the Kentucky serovar, followed by S. e. Montevideo (10\%) and S. e. Enteritidis (9.4\%) (USDA 2013). A comparison of phenotypic traits of serovar Kentucky and other poultry S. e. isolates revealed that this serovar was more sensitive to exposure to $\mathrm{pH} 2.5$ than most other Salmonella isolates (Joerger et al. 2009); however, when growth of S. e. Kentucky 3795 in medium adjusted to $\mathrm{pH} 5.5$ with $\mathrm{HCl}$ was compared to that of S. e. Enteritidis Nal ${ }^{\mathrm{R}}$, the Kentucky strain was able to grow better at this $\mathrm{pH}$ than the Enteritidis strain. Microarray-based gene expression analysis of the two strains exposed to $\mathrm{HCl}$-induced $\mathrm{pH} 5.5$ revealed few distinct differences between the gene expression patterns of the two isolates, but a prominent difference involved the $h d e B$-like gene that appears not to be expressed in the Kentucky isolate (Joerger and Choi 2015). Among other genes or open reading frames that showed differences in expression was the gene previously designated as/A. This gene, corresponding to locus SEN0085, STM0084 and SeKA_A4361 in S. e. Enteritidis, Typhimurium and Kentucky, respectively is predicted to encode a sulfatase-like protein. Upon exposure to medium with an $\mathrm{HCl}$-induced $\mathrm{pH}$ of 5.5, the Kentucky strain responded with a more than 5-fold increase in mRNA expression signal, whereas essentially no change in the corresponding signal for the Enteritidis strain was observed (Joerger et al. 2012). Thus, it is of interest to corroborate these results with data from enzyme activity and growth data.

The role of asIA in Salmonella's interaction with hosts or the environment is currently not well understood. Screening of transposon mutant libraries indicated that insertions in STM0084 did not have a strong impact on competitiveness of the mutant strains in in-vivo assays with mice injected with mutants and wild type (Chaudhuri et al. 2009), but when chickens, cattle and pigs were infected orally with the transposon mutants, mutants with insertions in STM0084 were less competitive (Chaudhuri et al. 2013). This observation suggests a possible role of this gene in host interactions in the GI tract. Das et 
al. (2013) deleted asIA in S. e. Typhimurium LT2 and demonstrated that it is expressed under mild acid conditions, but not at $\mathrm{pH}$ 7. Interestingly, the authors also showed that the enzyme that could potentially yield a carbon and/or sulfur source, was not regulated by sulfate or glucose.

In an attempt to further our understanding of the role of as/A and its potentially differential regulation in S. e. Enteritidis $\mathrm{Nal}^{\mathrm{R}}$ and Kentucky 3795, the gene was deleted in the current study and the utilization of sulfate ester compounds by the mutant and wild-type strains was assayed. The competitiveness of the mutants versus the wild-type strains in cell-invasion assays was also determined. The genes corresponding to SEN0085 in S. enterica Enteritidis Nal ${ }^{R}$ and SeKA_A4361 in S. enterica Kentucky 3795 were replaced with kanamycin-resistance cartridges as previously described (Joerger and Choi 2015) by utilizing Lambda red-mediated gene replacement. The 3'

TAAATGAATATGTGATAAAGTTACTGACTACAGGTATAATAATGTGTAGGCTGGAGCTGCTTC 5' and 3' ACACATATTCTTACCCGGAAGG 5' forward primers and 3' TAAATGAATATGTGATAAAGTTACTGACTACAGGTATAATAATGTGTAGGCTGGAGCTGCTTC 5' ${ }^{\prime}$ and 3'GCCTTAAATCGCTGACCAATCG5' reverse primers were used for mutagenesis and to confirm the success of the procedure respectively. The wild-type and mutant S. e. strains were then grown and maintained on tryptic soy agar (TSA) and TSA with kanamycin $(40 \mu \mathrm{g} / \mathrm{mL})$, respectively for growth studies with different potential sulfur sources. Das et al. (2013) suggested that the enzyme may have a role in utilization of sulfated glycans in the host. The mouth and digestive tracts are rich in sulphomucins, predominantly $\mathrm{N}$-acetylglucosamine 6-sulphate, galactose 6-sulphate, galactose 3-sulphate and galactose 4-sulphate (Roberton and Wright 1997). While sulphomucins limit mucin degradation by mucin-degrading bacterial enzymes and protect the underlying luminal surface, they are also a target for certain bacteria that hydrolyze the protective layer of sulfated glycans and establish infection. The wildtypes and mutant strains of S. e. Kentucky 3795 and S. e. Enteritidis Nal ${ }^{R}$ strains were inoculated into 3[N-morpholino] propane sulfonic acid (MOPS) Minimal Medium (Neidhardt et al. 1974) in which the 
MOPS component was replaced by 2-[N-morpholino] ethane sulfonic acid (MES) at the same molarity and glycerol at $50 \mathrm{mM}$ was the sole carbon source.

Das et al. (2013) had determined AlsA activity with cells grown at pH 5.5 in the presence of MOPS. MES was chosen in the current study as it exhibits better buffering capacity than MOPS at this $\mathrm{pH}$. When sulfatase activity in MES medium buffered at $\mathrm{pH} 5.5$ was compared to that obtained with cells grown in MOPS medium with the same starting $\mathrm{pH}$, it was observed that the activity of cells grown in MES medium was lower than that of cells grown in MOPS medium (data not shown). Measurements of the $\mathrm{pH}$ of the cultures showed that MOPS medium was unable to maintain the initial $\mathrm{pH}$ and the $\mathrm{pH}$ dropped to below 4 after $24 \mathrm{~h}$. This observation suggested that expression of alsA could possibly be higher at a $\mathrm{pH}$ lower than 5.5. Therefore, sulfatase activity assays were done with MES medium pH 3.75 to 6.5 in increments of $0.25 \mathrm{pH}$ units. The results for sulfatase activity after $24 \mathrm{~h}$ are shown in Table 1 and these data indicate that the activity is highest a $\mathrm{pH}$ of 4.5 to 4.75 . Therefore, growth studies with sulfatestarved wild-type cells and potassium 4-nitrophenyl sulfate (Sigma) as sulfate source were carried out at pH 4.5, 4.75, 5 and 5.5. Growth was considerably higher pH 5.5 than the other pHs tested (data not shown). Therefore, growth studies with different sugar sulfates were carried out at this $\mathrm{pH}$. For these studies, cells were first grown for $24 \mathrm{~h}$ at $30^{\circ} \mathrm{C}$ with shaking in MES medium without added sulfate and with a $\mathrm{pH}$ adjusted to 7 with $\mathrm{KOH}$. The cells were pelleted by centrifugation, re-suspended in sulfate-free MES-containing minimal medium with added glycerol at pH 5.5 and cultured for an additional $24 \mathrm{~h}$ under the same conditions. Cells were harvested by centrifugation and resuspended in sulfate free MEScontaining medium with added glycerol, $\mathrm{pH} 5.5$ at an initial $\mathrm{OD}_{600}$ of 0.05 . Ninety- $\mu \mathrm{L}$ aliquots of the cell suspensions were pipetted into wells of a 96-well microtiter plate and $10 \mu \mathrm{L}$ of either $1 \mathrm{mM} \mathrm{K}_{2} \mathrm{SO}_{4}$, sterile deionized water or $1 \mathrm{mM}$ of filter-sterilized sulfur sources in deionized water was added. The following sulfur sources were used: $D$-galactose 4-sulfate (Sigma); $D$-mannose 6-sulfate (Sigma); $D$ - 
galactose 6-sulfate (Sigma); chondroitin sulfate (Alfa Aesar); heparin sodium salt (Sigma-Aldrich); potassium 4-nitrophenyl sulfate (Sigma).

Growth in the presence of the above mentioned sole source of sulfate was monitored by reading the optical density with a plate reader (Biotek Instruments Inc.) at $600 \mathrm{~nm}$. Each culture condition was replicated in four wells and the average of the readings from the four wells were calculated. The difference between the $\mathrm{OD}_{600}$ of the wells containing $1 \mathrm{mM} \mathrm{K}_{2} \mathrm{SO}_{4}$ and those without added sulfate was set at $100 \%$ and compared to the difference between the $\mathrm{OD}_{600}$ obtained by the culture with the different organic sulfur sources and the $\mathrm{OD}_{600}$ of the cultures without added sulfate. Neither the wild types nor mutant strains of S. e. Kentucky 3795 and S. e. Enteritidis Nal ${ }^{R}$ showed any difference (Tuckey's test; $\mathrm{p}<0.05$ ) in growth. Thus as/A does not play a role in the utilization of the tested sulfated glycans as suggested by Das et al. (2013). In contrast, the wild-type strains were able to utilize 1 mM 4nitro phenyl sulfate as a sulfur source nearly to the extent as $1 \mathrm{mM} \mathrm{K}_{2} \mathrm{SO}_{4}$ (Fig. 1).

Sulfated phenolic compounds are not uncommon in nature and can also be found in proteins in the form of tyrosine-o-sulfate. One can speculate that this compound could be used by Salmonella as a source of sulfur and the amino acid, or that the hydrolysis of the ester bond could modulate certain cellular activities. For example, it is known that tyrosine sulfatation of gastrin, a hormone involved in regulating gastric acid secretion and growth of the mucosa in the gastrointestinal tract modifies the activity of the hormone (Jensen et al 1981). Tyrosine sulfate was synthesized for this study according to Liu et al. (2009). The compound was resolved on a Waters preparative HPLC system equipped with mass spectrometric detection (negative ionization) using XBridge ${ }^{\circledR}$ BEH Prep OBD ${ }^{\text {TM }}$ Amide $(19 \times 50 \mathrm{~mm})$ column, $5 \mu \mathrm{m}$ pore-size, with a linear gradient of $5 \%$ to $40 \%$ water in acetonitrile over 5 minutes), when added as sole sulfur source, the synthesized tyrosine sulfate did not lead to distinguishable levels of growth by mutant and wild type strains (Tuckey's test; $p>0.05$ ). It is possible that an enzyme other than that encoded by asIA is responsible for the release of some sulfur, by it is also possible that the tyrosine 
sulfate preparation contained some free sulfate (Fig. 1). Free sulfate could also be the reason for the minimal growth on heparin and chondroitin sulfate.

Another group of sulfated compounds arises from the metabolism of catecholamines. These compounds play a role in pathogenesis, including that of Salmonella (Spencer et al 2010). Growth of sulfate-starved wild and as/A mutant strains of S. e. Enteriditis and S. e. Kentucky in the presence of 4-hydroxy-3methoxyphenylglycol sulfate potassium salt(Sigma), a metabolite of norepinephrine degradation, did not reveal any difference, indicating that this compound is not a substrate for AslA (Fig 1). It is possible that only the actual hormone sulfate esters are recognized by the enzyme, but these esters were not available for this study.

To determine if the microarray-based differences in transcript accumulation of as/A mRNA between S. $e$. Enteritidis and S. e. Kentucky were reflected in the sulfatase activity at pH 5.5, the activity was monitored in the corresponding wild-type and as/A mutant strains as described by Das et al. (2013); except that the cells were grown in minimal medium with MES buffer and glycerol as carbon source. Activity on 5-bromo-4-chloro-3 indolyl sulfate was visualized on the respective minimal media solidified with $1.5 \%$ agar as production of a blue color. Sulfatase activity was observed with both wild-type strains strains with 4-nitrophenyl sulfate (Table 1) and 5-bromo-4-chloro-3 indolyl sulfate (data not shown), under appropriate acidic conditions. The sulfatase activity was generally slower to develop in the Enteritidis strain (data not shown), presumable because this strain is more affected by exposure to $\mathrm{pH}$ 5.5 (Joerger et al. 2009).

In vivo studies by Chaudhuri et al. (2013) in pigs, cattle and poultry and Das et al. (2014) in zebrafish have indicated the importance of $S$. e. Typhiumurium as/A in causing infection/survival within animal cells. Infection of confluent RAW 264.7 cells obtained by growing the cells at $37^{\circ} \mathrm{C}$ and $5 \% \mathrm{CO}_{2}$ for $48 \mathrm{~h}$ in Dulbecco's modified Eagle's medium (DMEM; Mediatech, Inc., Manassas, VA) containing $4.5 \mathrm{~g} / \mathrm{L}$ of glucose, L-glutamine, and sodium pyruvate amended with fetal bovine serum (FBS; HyClone, Logan, UT) 
at $10 \%(\mathrm{v} / \mathrm{v}), 4 \mathrm{mM}$ glutamax (Invitrogen, Carlsbad, CA), $\mathrm{NaHCO}_{3}$ (Mediatech) without antibiotics with equal number of $S$. enterica mutant and wild-type cells followed by assay of adhesion and invasion, done in triplicate, as described by Portnoy et al. (1988) did not reveal any difference between the competitive indexes (C.I) $(p>0.05)$ (Table 2). Since it is possible that in the competitive assay, mutant cells might benefit from the activity of simultaneously present wild-type cells, assays with RAW cells infected with the individual strains were also carried out. The results of these assays also demonstrated no difference in adhesion, invasion and intracellular persistence between wild-type and mutant strains (Table 3). Thus it appears that the role of AsIA in persistence of Salmonella typhimurium in animals as suggested by earlier experiments is not at the level of cell adhesion, invasion or intracellular growth.

Sulfatases, a highly conserved class of enzymes, hydrolyze a wide variety of sulfate esters and sulfamates and play a role in sulfur scavenging, mucin degradation and osmoprotection (Hansen et al 2004); however, the role played by the acid sulfatase in Salmonella enterica in metabolism or pathogenicity and the in-vivo substrate(s) for the as/A-encoded sulfatases remains unknown. It is interesting that the enzyme is able to utilize two quite distinct synthetic substrates, 5-bromo-4-chloro-3indolyl sulfate and 4-nitrophenyl sulfate, but not sugar sulfates. It is also interesting to note that apparently all sequenced Salmonella isolates encode AsIA enzymes with little differences in their amino acid sequences, but that the only other predicted AsIA-like sequences found so far are present only in Klebsiella sp. and in Enterobacter massiliensis (70 and 67\% sequence identity with Salmonella AsIA sequences, respectively). Why Salmonella maintains as/A in its genome and why similar enzymes are rare or not existent in other enteric bacteria is an interesting evolutionary question.

\section{Conflict of Interest}

The authors do not have any conflicts of interest. 
Acknowledgements

The authors thank Joe Fox, William Lambert and PapaNii Asare-Okai from the Department of Chemistry and Biochemistry at the University of Delaware for synthesizing and purifying tyrosine sulfate. The study was supported by Hatch funds.

\section{References}

Chaudhuri, R.R., Peter, S.P., Pleasance, S.J., Northen, H., Willers, C., Paterson, G.K., Cone, D.B., Allen, A.G., Owen, P.J., Shalom, G., Stekel, D.J., Charles, I.G., and Maskell, D.J. 2009. Comprehensive identification of Salmonella enterica Serovar Typhimurium genes required for infection of BALB/c mice.PLoS Pathog 5(7):e1000529. doi:10.1371/journal.ppat.1000529.

Chaudhuri, R.R., Morgan, E., Peters, S.E., Pleasance, S.J., Hudson, D.L., Davis, H.M., Wang, J., van Diemen, P.M., Buckley, A.M., Bowen, A.J., et al. 2013. Comprehensive assignment of roles for Salmonella Typhimurium genes in intestinal colonization of food-producing animals. PLoS Genet; 9(4): e1003456. doi:10.1371/journal.pgen.1003456

Das, S., Singh, S., McClleland, M., Frost, S., and Gyaneshwar, P. 2013. Characterization of an acidinducible sulfatase in Salmonella enterica Serovar Typhimurium. Appl Environ Microbiol 79(6):2092-95.

Das, S. Functional and genetic characterization of sulfatases in Salmonella enterica serovar Typhimurium 2014.. Theses and Dissertations. University of Wisconsin-Milwaukee. Paper 677.

Hanson, S.R., Best, M.D., and Wong, C-H. Sulfatases: Structure, mechanism, biological activity, inhibition and synthetic utility. 2004. Angew Chem Int Ed 43:5736-63.

Jensen, S.L., Holst, J.J., Nielsen, O.V., and Rehfeld, J.F. 1981. Effect of sulfation of CCK-8 on its stimulation of the endocrine and exocrine secretion from the isolated perfused porcine pancreas. Digestion 22:305-309. 
Joerger, R.D., Sartori, C.A., and Kniel, K.E. 2009. Comparison of genetic and physiological properties of Salmonella enterica isolates from chicken reveals one major difference between serovar Kentucky and other serovars: Response to acid. Foodborne Pathog Dis:6:503-512.

Joerger, R.D., Sartori, C., Frye, J.G., Turpin, J.B., Schmidt, C., McClelland, M., and Porwollik, S. 2012. Gene expression analysis of Salmonella enterica Enteritidis $\mathrm{Nal}^{\mathrm{R}}$ and Salmonella enterica Kentucky 3795 exposed to $\mathrm{HCl}$ and acetic acid in rich medium. Foodborne Pathog Dis: 9(4):331-337.

Joerger, R.D., and Choi, S. 2015. Contribution of hdeB-like gene (SEN 1493) to survival of Salmonella enterica Entreritidis $\mathrm{Nal}(\mathrm{R})$ at $\mathrm{pH}$ 2. Foodborne Pathog Dis:9(4):331-7.

Liu, C.C., Cellitti, S.E., Geierstanger, B.H., and Schultz, P.G. 2009. Efficient expression of tyrosine sulfated proteins in E. coli using an expanded genetic code. Nat Protocols:4(12):1784-89.

Neidhardt, F.C., Bloch, P.L., and Smith, D.F. 1974. Culture medium for enterobacteria. J Bacteriol:119:736-47.

Portnoy, D.A., Jacks, P.S., and Hinrichs, D. J. 1988. Role of hemolysin for the intracellular growth of Listeria monocytogenes. J Exp Med:167: 1459-71.

Roberton, A.M., and Wright, D.P. 1997. Bacterial glycosulphatases and sulphomucin degradation. Canc J Gastroenterol:11(4):361-66.

Spencer, H., Karavolos, M.H., Bulmer, D.M., Aldrige, P., Chhabra, S.R., Winzer, K., Williams, P., and Khan, C.M.A. 2010. Genome-wide transposon mutagenesis identifies a role for host neuroendocrine stress hormones in regulating the expression of virulence genes in Salmonella. J Bacteriol:192(3):714-724.

United States Department of Agriculture. Serotypes Profile of Salmonella Isolates from Meat and Poultry Products January 1998 through December 2013. http://www.fsis.usda.gov/wps/wcm/connect/c7b5903c-8e8b-4f85-9b5c12eaf990d2dd/Salmonella-Serotype-Annual-2013.pdf?MOD=AJPERES 
Figure Caption

Fig. 1: Growth in the presence of potential sulfur sources as percentage of corresponding growth in the presence of $1 \mathrm{mM}$ K2SO4. Percentage was calculated as follows: (O.D600 in presence of sulfur source O.D600 in absence of sulfur source/O.D600 in presence of 1mM K2SO4 - O.D 600 in absence of sulfur source)*100. Except for 4-nitrophenyl sulfate ( $p=0.015$ and 0.026 (Tuckey's test) for S. e. Enteritis NalR and Enterititids NaIR $\Delta$ aslA and S. e. Kentucky 3795 and Kentucky 3795, respectively), no differences in growth between wild type and mutant strains was observed. Data are based on at least three independent assays. 
Table 1 . Sulfatase activity as determined by p-nitrophenyl sulfate assay of cultures grown in minimal MES medium at different pHs for $24 \mathrm{~h}$. The values are the average of three independent assays. Sulfatase activity is expressed as Miller units where 1 unit $=1000 * A_{420}-\left(1.75^{*} A_{550}\right) /\left(t^{*} V^{*} A_{600}\right)$ where $\mathrm{t}=$ time of reaction and $\mathrm{V}=$ volume of culture assayed.

\begin{tabular}{ccccc}
$\mathrm{pH}$ & S.e. Enteritidis Nal & S. e. Enteritidis Nal & & S. e. Kentucky 3795 \\
& & $\Delta a s / A$ & S.e. Kentucky 3795 & $\Delta a s / A$ \\
\hline 3.75 & $37.21 \pm 8.88$ & $0.00 \pm 0.01$ & $60.85 \pm 30.95$ & $2.80 \pm 4.81$ \\
4.0 & $62.10 \pm 19.81$ & $0.00 \pm 0.01$ & $44.27 \pm 31.08$ & $-2.80 \pm 4.81$ \\
4.25 & $71.64 \pm 21.79$ & $0.083 \pm 1.45$ & $86.20 \pm 53.06$ & $-1.60 \pm 2.69$ \\
4.5 & $106.40 \pm 10.99$ & $1.10 \pm 1.93$ & $65.39 \pm 47.71$ & $0.14 \pm 0.24$ \\
4.75 & $130.01 \pm 33.71$ & $0.55 \pm 0.97$ & $65.25 \pm 42.34$ & $-1.58 \pm 2.74$ \\
5.0 & $19.89 \pm 23.53$ & $0.55 \pm 0.97$ & $24.74 \pm 32.82$ & $3.13 \pm 5.41$ \\
5.25 & $3.19 \pm 8.07$ & $1.58 \pm 1.41$ & $4.10 \pm 5.58$ & $0.03 \pm 1.59$ \\
5.5 & $1.20 \pm 1.33$ & $0.77 \pm 2.83$ & $0.88 \pm 0.80$ & $0.18 \pm 0.70$ \\
5.25 & $1.75 \pm 2.69$ & $0.88 \pm 0.54$ & $1.40 \pm 0.86$ & $1.20 \pm 1.25$ \\
6.0 & $1.71 \pm 1.38$ & $1.39 \pm 0.98$ & $0.80 \pm 0.28$ & $0.42 \pm 0.32$ \\
6.25 & $1.65 \pm 1.56$ & $2.06 \pm 2.32$ & $1.00 \pm 1.27$ & $0.54 \pm 3.84$ \\
6.5 & $1.80 \pm 3.52$ & $1.79 \pm 2.41$ & $0.50 \pm 0.87$ & $0.98 \pm 0.82$ \\
\hline
\end{tabular}


Table 2: Competitive Index values of S. e. wild-type and $\triangle a s / A$ mutant strains during adhesion, invasion and persistence in RAW 264.7 cells

\begin{tabular}{lccc} 
Strains & Adhesion & $\begin{array}{c}\text { Competitive index } \\
\text { Invasion (1 h post } \\
\text { addition of bacteria) }\end{array}$ & $\begin{array}{c}\text { Persistence (24 h post } \\
\text { addition of bacteria) }\end{array}$ \\
\hline $\begin{array}{l}\text { S. e. Enteritidis Nal }{ }^{R} / \text { S. e. } \\
\text { Enteritidis Nal }{ }^{R} \Delta a s / A\end{array}$ & $0.49(0.26)$ & $0.33(0.13)$ & $0.27(0.47)$ \\
$\begin{array}{l}\text { S. e. Kentucky 3795/S. e. } \\
\text { Kentucky } 3795 \Delta a s / A\end{array}$ & $0.51(0.41)$ & $0.25(0.31)$ & $0.19(0.83)$ \\
\hline
\end{tabular}

${ }^{a}$ Competitive index values were calculated as the output ratio of the mutant to wild type bacteria divided by input ratio of mutant to wild type bacteria. The values in parentheses represent $p$ values. 
Table3: Adhesion, invasion and persistence of S. e. Enteritidis Nal ${ }^{R}$ and S. e. Kentucky 3795 wild-type and $\Delta a s / A$ cells added to RAW 264.7 cells

\begin{tabular}{|c|c|c|c|c|}
\hline Strains & $\begin{array}{l}\text { Inoculum added } \\
\text { to RAW cell } \\
\text { culture }\end{array}$ & $\begin{array}{c}\text { S. } e \text {. cells } \\
\text { attached to RAW } \\
\text { cells after } 1 \mathrm{~h}\end{array}$ & $\begin{array}{c}\text { S. e. cells } \\
\text { internalized after } \\
2 \mathrm{~h}\end{array}$ & $\begin{array}{c}\text { S. } e \text {. cells } \\
\text { persisting in RAW } \\
\text { cells } 24 \text { h after } \\
\text { inoculation }\end{array}$ \\
\hline S. e. Enteritidis $\mathrm{Nal}^{\mathrm{R}}$ & $8.14 \pm 0.43^{\mathrm{a}}$ & $6.63 \pm 0.57$ & $5.52 \pm 0.11$ & $6.21 \pm 1.59$ \\
\hline S. e. Enteritidis $\mathrm{Nal}^{\mathrm{R}} \Delta a s / A$ & $8.20 \pm 0.24$ & $6.70 \pm 0.21$ & $5.50 \pm 0.00$ & $5.97 \pm 1.96$ \\
\hline S. e. Kentucky 3795 & $8.07 \pm 0.53$ & $6.54 \pm 0.19$ & $5.71 \pm 0.40$ & $5.87 \pm 1.39$ \\
\hline S. e. Kentucky $3795 \Delta a s / A$ & $7.91 \pm 0.46$ & $6.21 \pm 0.60$ & $4.97 \pm 0.48$ & $5.25 \pm 2.12$ \\
\hline
\end{tabular}

${ }^{a}$ Mean $\log _{10} \mathrm{cfu} /$ well \pm standard deviation of three separate trials 


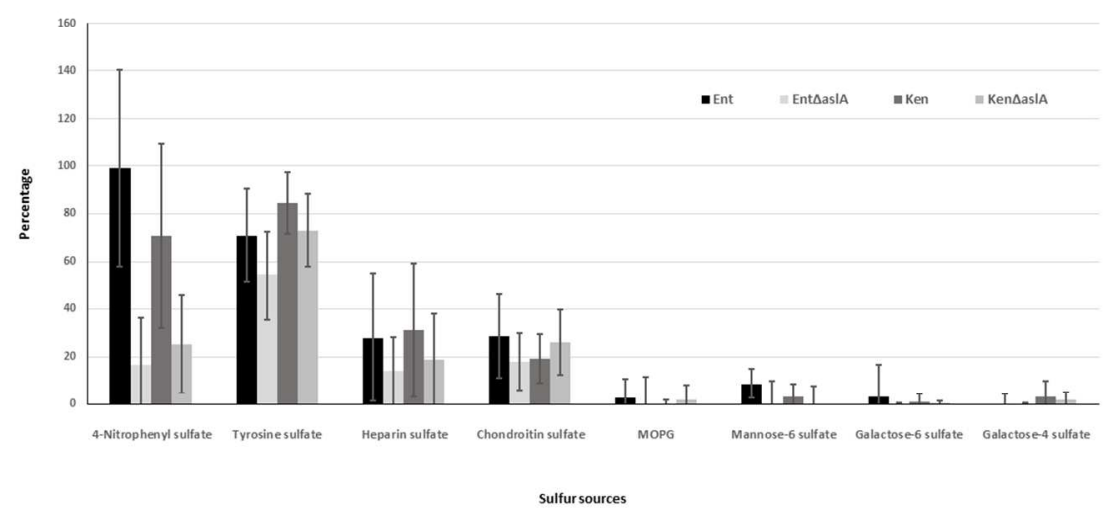

Fig. 1: Growth in the presence of potential sulfur sources as percentage of corresponding growth in the presence of $1 \mathrm{mM} \mathrm{K2SO4.} \mathrm{Percentage} \mathrm{was} \mathrm{calculated} \mathrm{as} \mathrm{follows:} \mathrm{(O.D600} \mathrm{in} \mathrm{presence} \mathrm{of} \mathrm{sulfur} \mathrm{source} \mathrm{-}$ O.D600 in absence of sulfur source/O.D600 in presence of 1mM K2SO4 - O.D 600 in absence of sulfur source)*100. Except for 4-nitrophenyl sulfate $(p=0.015$ and 0.026 (Tuckey's test) for S. e. Enteritis NalR and Enterititids NaIR $\Delta$ asIA and S. e. Kentucky 3795 and Kentucky 3795, respectively), no differences in growth between wild type and mutant strains was observed. Data are based on at least three independent assays.

$338 \times 190 \mathrm{~mm}(96 \times 96 \mathrm{DPI})$ 